\title{
APOE genotype and age modifies the correlation between cognitive status and metabolites from hippocampus by a 2D ${ }^{1}$ HMRS in non-demented elders
}

Zhenyu Yin, Wenbo Wu, Renyuan Liu, Xue Liang, Tingting Yu, Xiaoling Chen, Jie Feng, Aibin Guo, Yu Xie, Haiyan Yang, Mingmin Huang, Chuanshuai Tian, Bing Zhang, Yun Xu

Purpose To examine the associations among age, Apolipoprotein E (APOE) genotype, metabolic changes in the hippocampus detected by $2 \mathrm{D}{ }^{1} \mathrm{H}$ magnetic resonance spectroscopy (MRS), and neuropsychological measures of cognition in non-demented elders. Materials and Methods We studied a cohort of 16 cognitively normal controls $(\mathrm{CN})$ and 11 amnestic mild cognitive impairment $(\mathrm{aMCl})$ patients between 66 and 88 years old who were genotyped for APOE genetic polymorphism. Measurements of 2D ${ }^{1} \mathrm{H}-\mathrm{MRS}$ metabolites were obtained in the hippocampus region. Adjusting by age among all subjects, the association between metabolic changes and cognitive function was measured by Spearman partial rank-order correlation. The effect of APOE status was measured by separating the subjects into APOE genotype subgroups, including the APOE\&4 carriers and APOE\&4 non-carriers. Results In contrast to the CN group matched with age, gender, and education, a MCl patients showed increased myo-inositol $(\mathrm{ml}) /$ Creatine $(\mathrm{Cr})$ ratio only in the right hippocampus. No differences were noted on $\mathrm{N}$-acetylaspartate (NAA)/Cr and ml/NAA from bilateral hippocampus, and so was $\mathrm{ml} / \mathrm{Cr}$ ratio in left hippocampus between aMCl and $\mathrm{CN}$. The $\mathrm{ml} / \mathrm{Cr}$ ratio from the right hippocampus in non-demented elders was negatively correlated with Montreal Cognitive Assessment (MoCA) scores. Whether \&4 genotype or age was added as a covariate, none of the correlation effects remained significant. Additionally, adjusting for age and APOE genotype together, there was no significant correlation between them. Conclusion Since the higher $\mathrm{ml} / \mathrm{Cr}$ from the right hippocampus of the patients with $\mathrm{aMCl}$ than those from $\mathrm{CN}$, the $\mathrm{ml} / \mathrm{Cr}$ could be a more specific predictor of general cognitive function in aMCl patients. There is an association between higher $\mathrm{ml} / \mathrm{Cr}$ in right hippocampus and worse cognitive function for the non-demented older adults, and the correlation could be modified by APOE status and age. That provided a window on objectively understanding the mechanism between the brain metabolites and the influence factors in non-demented elders. 


\section{PeerJ Reviewing Manuscript}

5

6

\section{9}

1These two authors contributed equally to this work as co-first author.

18

\section{APOE genotype and age modifies the correlation between cognitive status and} metabolites from hippocampus by a 2D ${ }^{1} \mathrm{HMRS}$ in non-demented elders

Zhenyu Yin ${ }^{1, \mathrm{a}}$, Wenbo Wu ${ }^{1, \mathrm{~b}}$, Renyuan Liu ${ }^{\mathrm{c}}$, XueLiang ${ }^{\mathrm{d}}$, Tingting Yu ${ }^{\mathrm{a}}$, Xiaoling Chen ${ }^{\mathrm{a}}$, Jie Feng $^{\mathrm{a}}$, Aibin Guo ${ }^{\mathrm{a}}$, Yu Xie ${ }^{\mathrm{a}}$, Haiyan Yang ${ }^{\mathrm{a}}$, Mingmin Huang ${ }^{\mathrm{a}}$, ChuanshuaiTian ${ }^{\mathrm{d}}$ Bing Zhang*,d, Yun $\mathrm{Xu}^{*}{ }^{* \mathrm{c}}$

a:Department of Geriatrics, The Affiliated Drum Tower Hospital of Nanjing University Medical School, Nanjing, China.

b:Department of Neurology, The Affiliated Drum Tower Hospital of Nanjing Medical University, Nanjing, China.

c:Department of Neurology, The Affiliated Drum Tower Hospital of Nanjing University Medical School, Nanjing, China.

$\mathrm{d}$ :Department of Radiology, The Affiliated Drum Tower Hospital of Nanjing University Medical School, Nanjing, China.

* Corresponding author: These two authors contributed to this work equally. Tel.: +86 25 8310 5102; E-mail address: zhangbing_nanjing@vip.163.com (Bing Zhang) and xuyun20042001@aliyun.com(Yun Xu). 


\section{PeerJ Reviewing Manuscript}

\section{Abstract}

22

23

24

25

\section{Purpose}

To examine the associations among age, Apolipoprotein E (APOE) genotype, metabolic changes in the hippocampus detected by $2 \mathrm{D}{ }^{1} \mathrm{H}$ magnetic resonance spectroscopy (MRS), and neuropsychological measures of cognition in non-demented elders.

\section{Materials and Methods}

We studied a cohort of 16 cognitively normal controls $(\mathrm{CN})$ and 11 amnestic mild cognitive impairment (aMCI) patients between 66 and 88 years old who were genotyped for APOE genetic polymorphism. Measurements of $2 \mathrm{D}^{1} \mathrm{H}-\mathrm{MRS}$ metabolites were obtained in the hippocampus region. Adjusting by age among all subjects, the association between metabolic changes and cognitive function was measured by Spearman partial rank-order correlation. The effect of APOE status was measured by separating the subjects into APOE genotype subgroups, including the APOE\&4 carriers and APOE 4 non-carriers.

\section{Results}

In contrast to the $\mathrm{CN}$ group matched with age, gender, and education, aMCI patients showed increased myo-inositol $(\mathrm{mI}) /$ Creatine $(\mathrm{Cr})$ ratio only in the right hippocampus. No differences were noted on $\mathrm{N}$-acetylaspartate (NAA)/Cr and mI/NAA from bilateral hippocampus, and so was $\mathrm{mI} / \mathrm{Cr}$ ratio in left hippocampus between aMCI and $\mathrm{CN}$. The $\mathrm{mI} / \mathrm{Cr}$ ratio from the right hippocampus in non-demented elders was negatively correlated with Montreal Cognitive Assessment (MoCA) scores. Whether $\varepsilon 4$ genotype or age was added as a covariate, none of the correlation effects remained significant. Additionally, adjusting for age and APOE genotype together, there was no significant correlation between them. 


\section{PeerJ Reviewing Manuscript}

43

44

45

46

47

48

49

\section{Conclusion}

4 Since the higher $\mathrm{mI} / \mathrm{Cr}$ from the right hippocampus of the patients with aMCI than those from

$5 \mathrm{CN}$, the $\mathrm{mI} / \mathrm{Cr}$ could be a more specific predictor of general cognitive function in aMCI patients. There is an association between higher $\mathrm{mI} / \mathrm{Cr}$ in right hippocampus and worse cognitive function for the non-demented older adults, and the correlation could be modified by APOE status and age. That provided a window on objectively understanding the mechanism between the brain metabolites and the influence factors in non-demented elders. 


\section{PeerJ Reviewing Manuscript}

\section{Introduction}

The proton magnetic resonance spectroscopy $\left({ }^{1} \mathrm{HMRS}\right)$ is unique among diagnostic imaging modalities because the signals from several different metabolites are measured. It is a potential metabolic marker in Alzheimer's disease (AD) for both early diagnoses and evaluating treatment effects(Graff-Radford \& Kantarci 2013; Murray et al. 2014; Tumati et al. 2013). MRS allows regional measurement of metabolites including myo-Inositol (mI),choline (Cho), $\mathrm{N}$-acetyl aspartate (NAA), and creatine(Cr).Cr is typically used as an internal reference to control for variability in measurement because it remains unchanged in $\mathrm{AD}$ (Kantarci 2007). The $\mathrm{mI} / \mathrm{Cr}$ ratio is associated with glia and elevated levels with glial proliferation. Glial and microglial activity raises the possibility that elevated $\mathrm{mI}$ represents inflammation which is an early event in the evolution of AD pathology(Graff-Radford \& Kantarci 2013).

However, more and more evidences showed that despite of $\mathrm{mI}$ initially changed in early $\mathrm{AD}, \mathrm{mI} / \mathrm{Cr}$ was not related to the pathological severity of $\mathrm{AD}$ and could not predict the $\mathrm{AD}$ progression. For example, an autopsy study showed the subjects with a low likelihood of AD and sparse neuritic plaques had higher $\mathrm{mI} / \mathrm{Cr}$ ratios than the subjects with an intermediate likelihood of AD and moderate neuritic plaques (Kantarci et al. 2008). A longitudinal study also found the annual percent change in $\mathrm{mI} / \mathrm{Cr}$ ratios was not different between amnestic subtype of MCI (aMCI)-stable and aMCI-converter who progressed to AD during follow up(Kantarci et al. 2007). Furthermore, the mI levels were found to be associated with general cognition (such as MMSE, MoCA) in one study (Rose et al. 1999), but not associated with Mini-Mental State Examination (MMSE) in another study (Huang et al. 2001). Therefore, the 


\section{PeerJ Reviewing Manuscript}

71 association between metabolites and cognitive measures remains controversial.

72 There are some factors that potentially influence the cognitive impairment. Apo lipoprotein

73 E (APOE ) genotype is the best established susceptibility gene and has been shown to

74 influence age of onset(Mastaglia et al. 2013)and the underlying histopathology of

75 AD(Michaelson 2014).Carriers of the APOE\&4 allele have an increased risk of cognitive

76 decline(Kozauer et al. 2008). Age is another main factor affecting cognitive function. A study

77 using general linear model analysis demonstrated that older APOE\&4 carriers had significantly

78 higher $\mathrm{mI}$ than APOE\&3 homozygotes in a healthy aging normal population (Gomar et al.

79 2014). But it has been previously suggested that the APOE effect dissipated for old

80 individuals who were more than 80 year old.(Negash et al. 2009).

81 To the best of our knowledge, there is still no evidence for the effect of APOE genotype

82 and age on the relationship between metabolites and cognitive status in aMCI patients. So, our

83 primary objective was to determine the metabolic changes in the hippocampus measured by

$842 \mathrm{D}{ }^{1} \mathrm{HMRS}$ in aMCI patients compared with normal controls. We hypothesized that aMCI

85 patients have increased $\mathrm{mI} / \mathrm{Cr}$ ratio in the hippocampus compared with normal elderly. In

86 addition, APOE genotype and age may impact the correlation between metabolites and

87 cognitive status in aMCI patients. In this way, we might be able to elucidate the influence

88 factors on the association between metabolites and cognitive measures.

PeerJ reviewing PDF | (2015:04:4733:1:0:NEW 19 Jul 2015) 


\section{PeerJ Reviewing Manuscript}

89

90

91

92

93

94

95

96

97

98

99

100

101

102

103

104

105

\section{Methods and Materials}

\section{Participants}

Participants were recruited at the Memory clinic of Neurology Department in Nanjing

Drum Tower Hospital during a 19 months span from September 1, 2011 to April 31, 2013.

The study was approved by the Medical Research Ethics Committee of Nanjing Drum Tower

Hospital, Nanjing, China, and all the subjects' written informed consents were obtained

before the study. Participants were classified based on the clinical criteria and results of the

neropsychological tests into the aMCI and CN groups. Participants in aMCI group met the

Petersen's criteria(Petersen 2000; Petersen 2004), which included (a) memory complaint,

preferably confirmed by an informant; (b) objective memory impairment, adjusted for age and education; (c) normal or near-normal performance on general cognitive functioning and no or minimum impairment of daily life activities; (d) the Clinical Dementia Rating (CDR) score of 0.5; and (e) not meeting the criteria for dementia according to the DSM-IV (Diagnostic and Statistical Manual of Mental Disorders, 4rd edition, revised). Patients with aMCI were diagnosed by experienced neurologists. Cognitive normal controls $(\mathrm{CN})$ were identified as individuals who (a) had no cognitive complaints, (b) had a normal level of clinical rating scales, and (c) had no evidence of any abnormality examined by a conventional MRI.

Subjects were excluded if they met the following clinical characteristics: (a) those who have a clear history of stroke; (b) severe depression that led to aMCI (Hamilton Depression Rating Scale score $>24$ points)/ vascular dementia( Hachinski scores $\geq 7$ ); (c) other nervous system diseases, which can cause cognitive impairment (such as brain tumors, Parkinson's 


\section{PeerJ Reviewing Manuscript}

110 disease, encephalitis, and epilepsy); (d) cognitive impairment caused by traumatic brain injury;

111 (e) other systemic diseases, which can cause cognitive impairment, such as thyroid

112 dysfunction, severe anemia, syphilis, and HIV; and (f) a history of psychosis or congenital mental growth retardation.

114

\section{Cognitive Assessment}

All of subjects were evaluated using a standardized clinical evaluation protocol, which included Montreal Cognitive Assessment (MoCA), Mini-Mental State Examination (MMSE),

Scaling (HIS) and Hamilton Depression Scale(HAMD) to exclude vascular cognitive impairment and depression state. Memory and executive function was assessed through ADAS-cog test. Wechisler Adult Intelligence Scale including digital symbol and digital span were also tested for all participants.

\section{Genotpying}

125 Genotyping was conducted using Polymorphic DNA at two loci in APOE exon 4 by

126 amplicon sequencing methods to produce small polymerase chain reaction products that serve

127 as the templates for bidirectional sequencing. Participants with APOE genotype 2/2, 2/3 were

128 labeled 2 carriers, genotype 3/3 was labeled $\varepsilon 3$ homozygote, genotypes $3 / 4$ and $4 / 4$ were

129 labeled $\varepsilon 4$ carriers. 


\section{PeerJ Reviewing Manuscript}

131

132

133

134

135

136

137

138

139

140

141

142

143

144 hippocampus, respectively. The VOI (voxel of interest, $64 \times 32 \mathrm{~mm}$ in this study) of 2D-PRESS

145 was located on the transverse image of bilateral hippocampi, and its long axis is parallel with

146 the hippocampus referenced by sagittal $3 \mathrm{DT}_{1} \mathrm{~W}$ image, with the caution of avoiding the

147 surrounding bone, air and fat. We selected the hippocampus voxel (18 27) in the effective

148 voxel based on the hippocampal anatomy actual form. A voxel was considered eligible

149 whenever more than two-thirds of its area was located within hippocampus area. Finally the

150 average magnitude spectra per voxel were computed by summation of the voxel spectra from

151 the defined volume of interest (VOI) and division by the number of voxels(Shen et al. 2009;

Peer) reviewing PDF | (2015:04:4733:1:0:NEW 19 Jul 2015) 


\section{PeerJ Reviewing Manuscript}

152 Weis et al. 2014). The chemical shift distance was considered in the localization process by

153 double-checking the chemical shift voxels of NAA and mI, respectively. (Figure 1) The MRS

154 acquisition time was about 6 minutes and 6 seconds.

155 The MRS metabolite ratios were determined for NAA/Cr, $\mathrm{mI} / \mathrm{Cr}$ and $\mathrm{mI} / \mathrm{NAA}$. Ratios were

156 quantified automatically with Philips WorkStation software (Extended Workspace, EWS).

157 The measured $\mathrm{Cr}$ peak includes both the metabolites $\mathrm{Cr}$ and phosphocreatine and is thought to

158 be a reliable marker of brain energy metabolism, often used as a relatively stable reference

159 level (Kantarci 2007).

160

161

\section{Statistical Analyses}

162 Statistical analysis was performed by software (SPSS version 16.0; SPSS, Chicago, Ill) for

163 demographic and clinical data. For our primary analysis, we summarize associations between

164

cognition and ${ }^{1} \mathrm{H}-\mathrm{MRS}$ metabolite ratios using Spearman partial rank-order correlations which

165 we denote by "partial $r_{\mathrm{s}}$." Due to the limitation of our sample size, we used partial $r_{\mathrm{s}}$ to

166 quantify associations since it is a nonparametric correlation between 2 variables which does

167 not assume normally distributed data and therefore is preferable in this situation. Next, we

168 report partial Spearman rank-order correlations adjusting for age, gender, and education

169 among all subjects. The effect of APOE genotype on the association between cognitive

170 function and ${ }^{1} \mathrm{H}-\mathrm{MRS}$ metabolite ratios was adjusted by APOE genotype subgroups. We

171 separated the APOE $\varepsilon 4$ carriers $(\varepsilon 3 \varepsilon 4$ and $\varepsilon 4 \varepsilon 4)$ and APOE $\varepsilon 4$ non-carriers $(\varepsilon 2 \varepsilon 2, \varepsilon 2 \varepsilon 3$ and

172 APOEع3homozygotes) into two subgroups.

Peerj reviewing PDF | (2015:04:4733:1:0:NEW 19 Jul 2015) 


\section{PeerJ Reviewing Manuscript}

173 In summary, we tested for associations using Spearman partial rank-order correlations in

174 which we report $4 \mathrm{p}$ values: 1)the significance of associations between cognition and ${ }^{1} \mathrm{H}-\mathrm{MRS}$

175 metabolite ratios; 2) whether adding age to this model is significant; 3) whether adding APOE

176 to this model is significant; and 4) whether adding age and APOE to this model is significant.

177

178 RESULTS

\section{Subjects}

Characteristics of subjects are described in table 1. Subjects with Fazekas III and high Hachinski scores $(\geq 7)$ were excluded in this study in order to reduce and isolate the effect of vascular dementia. There was no significant difference between aMCI $(\mathrm{N}=11$; age: $79 \pm 6.5,69$ to 88 ; 2 female and 9 male; education years: $14 \pm 2.9,9$ to 16$)$ and $\mathrm{CN}(\mathrm{N}=16$; age: $74 \pm 5.5,66$ to 83 ; 4 female and 12 male; education years: $15 \pm 1.0,12$ to 16$)$ in age $(p=0.056)$, gender ( $p=0.675)$, and education $(p=0.342)$ by Mann-Whitney U test. Significantly lower cognitive

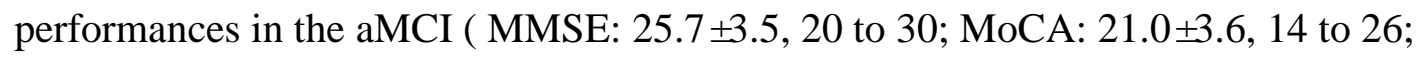

Hachinski: $3.64 \pm 2.42,0$ to 6 ; ADAS-cog: $10.2 \pm 6.27,2$ to 23 ) compared with the CN (MMSE:

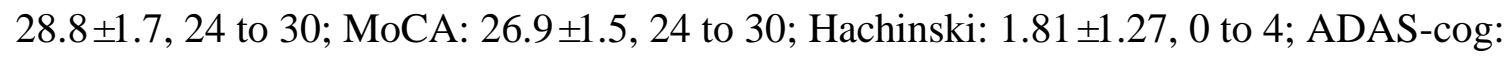
$5.5 \pm 2.98,1$ to 14 ) were observed( all $p$ values $<0.05$ ).

\section{${ }^{1} \mathrm{H}-\mathrm{MRS}$ metabolite ratios}

The characteristics of ${ }^{1} \mathrm{H}-\mathrm{MRS}$ metabolite ratios of bilateral hippocampi, including $\mathrm{NAA} / \mathrm{Cr}, \mathrm{mI} / \mathrm{Cr}$ and $\mathrm{mI} / \mathrm{NAA}$, are described in table 2 . We treated ${ }^{1} \mathrm{H}-\mathrm{MRS}$ metabolite ratio as a continuous variable in all analysis. Increased $\mathrm{mI} / \mathrm{Cr}$ in right hippocampus of aMCI 


\section{PeerJ Reviewing Manuscript}

195 subjects compared with $\mathrm{CN}$ was found by Mann-Whitney U test $(p=0.050)$ (Figure 2).

196 However, no significant difference in NAA/Cr in bilateral hippocampi and $\mathrm{mI} / \mathrm{Cr}$ in left

197 hippocampus was found (all $p$ values $>0.05$ ).

198

199 Correlation between ${ }^{\mathbf{1}} \mathrm{H}-\mathrm{MRS}$ metabolite ratios and cognitive function

200 The correlations between ${ }^{1} \mathrm{H}-\mathrm{MRS}$ metabolite ratios, age and cognition scores were

201 measured by Spearman partial rank-order correlations as described in table 3. Only $\mathrm{mI} / \mathrm{Cr}$ in

202 right hippocampus was enrolled in the association analysis since it was the only metabolite

203 ratio appeared significant difference between groups. The same principal was applied to

204 cognitive rating scales, as only five of them are shown in table 3. Age is a major factor of

205 cognition decline and AD neuropathology and therefore was also included in this analysis.

206 Higher $\mathrm{mI} / \mathrm{Cr}$ in right hippocampus was associated with worse overall cognitive

207 performance, including MMSE, MoCA, Hachinski, CDR and ADAS-cog. However, only the

208 correlation between $\mathrm{mI} / \mathrm{Cr}$ and MoCA is significant ( $\left.r_{\mathrm{s}}=-0.403, p=0.025\right)$. Age was

209 significantly associated with MMSE ( $\left.r_{\mathrm{s}}=-0.508, p=0.007\right), \operatorname{MoCA}\left(r_{\mathrm{s}}=-0.407, p=0.035\right)$ and

210 ADAS- $\operatorname{cog}\left(r_{\mathrm{s}}=0.469, p=0.014\right)$. However, no correlation between age and $\mathrm{mI} / \mathrm{Cr}$ in right

211 hippocampus was found $(\mathrm{p}=0.678)$.

212

213 Effect of APOE $\varepsilon 4$ allele and age on the association between cognitive function and

$214 \quad{ }^{\mathbf{1}} \mathbf{H}$-MRS metabolite ratios 


\section{PeerJ Reviewing Manuscript}

215 Since there was correlation between MoCA and $\mathrm{mI} / \mathrm{Cr}$, we further analyze the effect of

216 APOE and age on this association by partial correlation. No correlation was found between

217 cognition and $\mathrm{mI} / \mathrm{Cr}$ in right hippocampus after controlling for age $(r \mathrm{~s}=-0.358, p=0.073)$ as

218 described in table 4, indicating that there was an interaction with age for the association

219 between cognitive function and ${ }^{1} \mathrm{H}-\mathrm{MRS}$ metabolite ratios.

The effect of APOE status was measured by separating the subjects into APOE genotype

221 subgroups, the APOE $\varepsilon 4$ carriers $(n=5$, allele $\varepsilon 3 \varepsilon 4$ and $\varepsilon 4 \varepsilon 4)$ and APOE $\varepsilon 4$ non-carriers $(\mathrm{n}=22$,

222 allele $\varepsilon 2 \varepsilon 3$ and $\varepsilon 3 \varepsilon 3$ ). We did not find any differences in $\mathrm{mI} / \mathrm{Cr}$ (Figure $3 \boldsymbol{A}$ ) and cognition

223 scores (Figure 3B) between the 2 groups. No correlation was found between cognition and

$224 \mathrm{mI} / \mathrm{Cr}$ in right hippocampus in both APOE $\varepsilon 4$ carriers $(r \mathrm{~s}=-0.667, p=0.219)$ and APOE $\varepsilon 4$

225 non-carriers $(r s=-0.316, p=0.152)$ (Figure 4). Furthermore, there was no correlation between

226 cognitive function and ${ }^{1} \mathrm{H}-\mathrm{MRS}$ metabolite ratios in both APOE 4 carriers $(r s=-0.862$,

$227 p=0.138)$ and APOE $\varepsilon 4$ non-carriers $(r s=-0.354, p=0.115)$ after controlling for age, indicating

228 that the APOE status and age might influence the correlation between cognition and ${ }^{1} \mathrm{H}-\mathrm{MRS}$

229 metabolite ratios as shown in table 4. 


\section{PeerJ Reviewing Manuscript}

\section{Discussion}

Findings of this study indicated that the glial activity marker $\mathrm{mI} / \mathrm{Cr}$ from the right hippocampus increased in patients with aMCI compared with those from normal elderly. Furthermore, there is an association between higher $\mathrm{mI} / \mathrm{Cr}$ in right hippocampus and worse cognitive function in non-demented older adults and this relationship could be modified by APOE status and age.

The neurofibrillary tangles pathology of $\mathrm{AD}$ follow a typical progression from limbic to neocortical regions as AD advances(Braak \& Braak 1991). A similar temporal course of changes in these metabolites is seen with aMCI, a prodromal stage of AD (Knopman 2013; Petersen et al. 2009). Therefore, it is reasonable that we selected to measure metabolites in bilateral hippocampus known as the earliest involved limbic region in aMCI patients. Our findings are consistent with prior studies showing that aMCI patients have elevated myo-Inositol levels in right hippocampus, which is associated with glial proliferation (Miller et al. 1993). We did not find the changes in NAA/Cr from the hippocampus in our subject sample, which supports the hypothesis that the elevation of $\mathrm{mI} / \mathrm{Cr}$ ratio precedes the decrease in NAA/Cr ratio during the progression of aMCI, mild AD and $\mathrm{AD}$ (Kantarci et al. 2000). This finding is consistent with a previous ${ }^{1} \mathrm{H}$ MRS study in aMCI(Kantarci et al. 2000; Kantarci et al. 2007; Zhang et al. 2009), mild AD(Huang et al. 2001) and in presymptomatic carriers of the familial AD mutations(Godbolt et al. 2006) which suggested that $\mathrm{mI} / \mathrm{Cr}$ elevation is an early event in the progression of AD pathology . 


\section{PeerJ Reviewing Manuscript}

250

251

252

253

254

255

256

257

258

259

260

261

262

263

264

In an imaging-autopsy correlation study, the antemortem $\mathrm{mI} / \mathrm{Cr}$ levels correlated with the density of neuritic plaques in subjects at autopsy(Kantarci et al. 2008).If $\mathrm{mI} / \mathrm{Cr}$ is a marker associated with the amyloid pathology of $\mathrm{AD}$, then the higher $\mathrm{mI} / \mathrm{Cr}$ will be expected to relate with the worse cognitive performance. In our study, $\mathrm{mI} / \mathrm{Cr}$ ratios negatively correlated with the general cognition status (MoCA scores), which is in consistent with former studies (Jessen et al. 2000; Kantarci et al. 2002). Associations were present in regions where there was significant amyloid deposition, such as hippocampus. Based on this, we might expect to find an association between higher $\mathrm{mI} / \mathrm{Cr}$ and worse cognitive performance in bilateral hippocampus. However, we only found the $\mathrm{mI} / \mathrm{Cr}$ changed in right hippocampus, not in left.

There were published researches indicating that the rightward asymmetry of hippocampal connectivity observed in elderly controls was diminished in AD patients(Wang et al. 2006).

Based on this potentially asymmetric hippocampus function, it is reasonable that the metabolites might change in different rate or extent between bilateral hippocampus. However, due to small sample size limitation in our study, there is not sufficient evidence to support the hippocampus involved asymmetrically. The absence of this expected correlation requires further large sample and longitudinal investigation.

The association between the brain metabolites and cognition in old adults appear to be multifactorial, such as genotype and age. In humans, there are three common alleles of the APOE gene, numbered 2, 3 and 4. In line with prior research (Munoz \& Feldman 2000), APOE 4 is disproportionately represented in our patient sample (16.6\% of the patient sample was $4+$ compared to $11.5 \%$ of the control sample). Increasing researches showed that the 


\section{PeerJ Reviewing Manuscript}

271 APOE\&4 allele is associated with a greatly increased risk of AD (Strittmatter et al. 1993).

272 However, the function of the APOE protein, and its relationship with metabolites in the brain

273 remains mostly unknown. Although one study showed that myo-Inositol were significantly

274 increased in APOE\&4 carriers in a healthy aging normal population (Gomar et al. 2014), there

275 is still no evidence in aMCI carriers. In our cohort, the presence of an APOE $\varepsilon 4$ allele

276 influences the relationship between $\mathrm{mI}$ and cognitive function in non-demented people. We

277 dichotomized the non-demented subjects into APOE\&4 carriers and non-carriers groups, and

278 did not find any differences in $\mathrm{mI} / \mathrm{Cr}$ and cognition scores between the 2 groups. Within each

279 group, there was no correlation between the $\mathrm{mI} / \mathrm{Cr}$ ratio and MoCA scores, indicating APOE

280 as the mediator modified this relationship, since there was correlation between metabolites

281 and cognition before separating the genotyping. Further, we note that the $\mathrm{mI} / \mathrm{Cr}$ trends to

282 decrease and the cognition scores trends to increase with the presence of an APOE $\varepsilon 4$ allele.

283 There was relatively little cognitive disturbance in non-demented APOE 44 carriers in this

284 small cohort, suggesting the influence of additional mediators such as potential compensatory

285 progress in aMCI, which need further confirmation in the future (Kantarci et al. 2012).

286 Moreover, age is the main factors affecting cognitive function. But the age effects on

$287{ }^{1} \mathrm{H}-\mathrm{MRS}$ metabolites have been inconsistently described, have been small effect, or have been

288 dependent on metabolite and voxel placement(Haga et al. 2009). In our sample, we found the

289 negative correlation between age and MoCA, indicating cognition decline in old people,

290 which is in line with other studies (Ashworth et al. 2014; Yu et al. 2014). While using

291 controlling age as the covariates, the correlation between $\mathrm{mI} / \mathrm{Cr}$ ratio and MoCA scores

Peerj reviewing PDF | (2015:04:4733:1:0:NEW 19 Jul 2015) 


\section{PeerJ Reviewing Manuscript}

292

293

294

295

296

297

298

299

300

301

302

303

304

305

306

307

disappeared. Based on this result, age is another main factor affecting the correlation between metabolites and cognitive function. Further large cohort is required to confirm the age effect on the association.

Several other technique points about our study may be worth considering.

One potential concern is the metabolites from hippocampus measuring by the $2 \mathrm{D}{ }^{1} \mathrm{H}-\mathrm{MRS}$.

Compared with single voxel MRS, the surrounding tissue (i.e., fat, bone, air and cerebral spinal fluid) can be relatively easily avoided by selecting the usable voxels from the multi voxels in the field of volume, which making the metabolites from the relative pure hippocampus tissue. In addition, 2D MRS had more sampling points, and we could get more data. The mean value was more accurate and persuasive. Secondly, the metabolite measurements in this study were obtained from right and left hippocampus, respectively, which improved the quality of the shimming in the field of volume for each of the hippocampus. Thirdly, we controlled the data quality from multi-voxel chemical shift imaging ${ }^{1} \mathrm{H}$ MRS following several technical aspects: (1) using short echo time (TE $=32 \mathrm{~ms}$ ) in ${ }^{1} \mathrm{H}$ MRS acquisitions was critical to this study, because $\mathrm{mI}$ has a relatively short transverse relaxation time and can be quantified only at short echo times; (2) Because the various metabolites in the tissue of interest process are at different frequencies, as a result, the selected volume will be different for the different metabolites, i.e. chemical shift displacement. Therefore, the chemical shift distance were considered in to the localization process by double-checked the chemical shift voxels of NAA and mI, respectively. A limitation of our study is the insufficient follow-up on the cohort and the small 


\section{PeerJ Reviewing Manuscript}

313 sample size we scanned during the last 2 years. Overall, our in vivo ${ }^{1} \mathrm{H}$ MRS data are

314 consistent with the biochemical changes underlying the known pathology in each of the

315 related studies. Moreover, due to the small sample size limitation, we did not separate the

316 cohort into aMCI subtype with different cognitive domain impairment. Amnestic MCI has

317 higher risk at $\mathrm{AD}$ progression, and it is expected to have higher $\mathrm{mI} / \mathrm{Cr}$ ratio and stronger

318 correlation with APOE status.

319 In summary, we found $\mathrm{mI} / \mathrm{Cr}$ ratios from right hippocampus increased in aMCI, suggesting

320 glial proliferation changes could be a more specific predictor of general cognitive function in

321 aMCI patients. Furthermore, we demonstrated that the APOE status and age modified the

322 associations between $\mathrm{mI} / \mathrm{Cr}$ from right hippocampus measured by $2 \mathrm{D}{ }^{1} \mathrm{HMRS}$ and cognitive

323 function in non-demented subjects. The finding of the study is of significance in further

324 understanding the influence of changes of brain metabolites on cognitive functions, where age

325 and APOE genotype should be taken into consideration. 


\section{PeerJ Reviewing Manuscript}

\section{References}

Ashworth B, Dilks L, Hutchinson K, Hayes S, Moore M, Orozoco A, DeRoche K, Julian A, and Barnett O. 2014. A-67A Pilot Study of Age and Education Norms for the Montreal Cognitive Assessment. Arch Clin Neuropsychol 29:527-528.

Braak H, and Braak E. 1991. Neuropathological stageing of Alzheimer-related changes. Acta Neuropathol 82:239-259.

Godbolt AK, Waldman AD, MacManus DG, Schott JM, Frost C, Cipolotti L, Fox NC, and Rossor MN. 2006. MRS shows abnormalities before symptoms in familial Alzheimer disease. Neurology 66:718-722.

Gomar JJ, Gordon ML, Dickinson D, Kingsley PB, Ulug AM, Keehlisen L, Huet S, Buthorn JJ, Koppel J, Christen E, Conejero-Goldberg C, Davies P, and Goldberg TE. 2014. APOE genotype modulates proton magnetic resonance spectroscopy metabolites in the aging brain. Biol Psychiatry 75:686-692.

Graff-Radford J, and Kantarci K. 2013. Magnetic resonance spectroscopy in Alzheimer's disease. Neuropsychiatr Dis Treat 9:687-696.

Haga KK, Khor YP, Farrall A, and Wardlaw JM. 2009. A systematic review of brain metabolite changes, measured with $1 \mathrm{H}$ magnetic resonance spectroscopy, in healthy aging. Neurobiol Aging 30:353-363.

Huang W, Alexander GE, Chang L, Shetty HU, Krasuski JS, Rapoport SI, and Schapiro MB. 2001. Brain metabolite concentration and dementia severity in Alzheimer's disease: a (1)H MRS study. Neurology 57:626-632.

Jessen F, Block W, Traber F, Keller E, Flacke S, Papassotiropoulos A, Lamerichs R, Heun R, and Schild HH. 2000. Proton MR spectroscopy detects a relative decrease of $\mathrm{N}$-acetylaspartate in the medial temporal lobe of patients with AD. Neurology 55:684-688.

Kantarci K. 2007. 1H magnetic resonance spectroscopy in dementia. Br J Radiol 80 Spec No 2:S146-152.

Kantarci K, Jack CR, Jr., Xu YC, Campeau NG, O'Brien PC, Smith GE, Ivnik RJ, Boeve BF, Kokmen E, Tangalos EG, and Petersen RC. 2000. Regional metabolic patterns in mild cognitive impairment and Alzheimer's disease: A 1H MRS study. Neurology 55:210-217.

Kantarci K, Knopman DS, Dickson DW, Parisi JE, Whitwell JL, Weigand SD, Josephs KA, Boeve BF, Petersen RC, and Jack CR, Jr. 2008. Alzheimer disease: postmortem neuropathologic correlates of antemortem $1 \mathrm{H}$ MR spectroscopy metabolite measurements. Radiology 248:210-220.

Kantarci K, Lowe V, Przybelski SA, Weigand SD, Senjem ML, Ivnik RJ, Preboske GM, Roberts R, Geda YE, Boeve BF, Knopman DS, Petersen RC, and Jack CR, Jr. 2012. APOE modifies the association between Abeta load and cognition in cognitively normal older adults. Neurology 78:232-240.

Kantarci K, Smith GE, Ivnik RJ, Petersen RC, Boeve BF, Knopman DS, Tangalos EG, and Jack CR, Jr. 2002. 1H magnetic resonance spectroscopy, cognitive function, and apolipoprotein E genotype in normal aging, mild cognitive impairment and Alzheimer's disease. J Int Neuropsychol Soc 8:934-942.

Kantarci K, Weigand SD, Petersen RC, Boeve BF, Knopman DS, Gunter J, Reyes D, Shiung M, O'Brien PC, Smith GE, Ivnik RJ, Tangalos EG, and Jack CR, Jr. 2007. Longitudinal 1H MRS changes in mild cognitive impairment and Alzheimer's disease. Neurobiol Aging 28:1330-1339.

Knopman DS. 2013. Alzheimer disease biomarkers and insights into mild cognitive impairment. Neurology 80:978-980.

Kozauer NA, Mielke MM, Chan GK, Rebok GW, and Lyketsos CG. 2008. Apolipoprotein E genotype and lifetime cognitive decline. Int Psychogeriatr 20:109-123.

Mastaglia FL, Rojana-udomsart A, James I, Needham M, Day TJ, Kiers L, Corbett JA, Saunders AM, Lutz MW, and Roses AD. 2013. Polymorphism in the TOMM40 gene modifies the risk of developing sporadic inclusion

Peerj reviewing PDF | (2015:04:4733:1:0:NEW 19 Jul 2015) 


\section{PeerJ Reviewing Manuscript}

body myositis and the age of onset of symptoms. Neuromuscul Disord 23:969-974.

Michaelson DM. 2014. APOE epsilon4: the most prevalent yet understudied risk factor for Alzheimer's disease. Alzheimers Dement 10:861-868.

Miller BL, Moats RA, Shonk T, Ernst T, Woolley S, and Ross BD. 1993. Alzheimer disease: depiction of increased cerebral myo-inositol with proton MR spectroscopy. Radiology 187:433-437.

Munoz DG, and Feldman H. 2000. Causes of Alzheimer's disease. CMAJ 162:65-72.

Murray ME, Przybelski SA, Lesnick TG, Liesinger AM, Spychalla A, Zhang B, Gunter JL, Parisi JE, Boeve BF, Knopman DS, Petersen RC, Jack CR, Jr., Dickson DW, and Kantarci K. 2014. Early Alzheimer's Disease Neuropathology Detected by Proton MR Spectroscopy. J Neurosci 34:16247-16255.

Negash S, Greenwood PM, Sunderland T, Parasuraman R, Geda YE, Knopman DS, Boeve BF, Ivnik RJ, Petersen RC, and Smith GE. 2009. The influence of apolipoprotein E genotype on visuospatial attention dissipates after age 80. Neuropsychology 23:81-89.

Petersen RC. 2000. Mild cognitive impairment: transition between aging and Alzheimer's disease. Neurologia 15:93-101.

Petersen RC. 2004. Mild cognitive impairment as a diagnostic entity. J Intern Med 256:183-194.

Petersen RC, Roberts RO, Knopman DS, Boeve BF, Geda YE, Ivnik RJ, Smith GE, and Jack CR, Jr. 2009. Mild cognitive impairment: ten years later. Arch Neurol 66:1447-1455.

Rose SE, de Zubicaray GI, Wang D, Galloway GJ, Chalk JB, Eagle SC, Semple J, and Doddrell DM. 1999. A 1H MRS study of probable Alzheimer's disease and normal aging: implications for longitudinal monitoring of dementia progression. Magn Reson Imaging 17:291-299.

Shen J, Zhang L, Tian X, Liu J, Ge X, and Zhang X. 2009. Use of short echo time two-dimensional 1H-magnetic resonance spectroscopy in temporal lobe epilepsy with negative magnetic resonance imaging findings. J Int Med Res 37:1211-1219.

Strittmatter WJ, Saunders AM, Schmechel D, Pericak-Vance M, Enghild J, Salvesen GS, and Roses AD. 1993. Apolipoprotein E: high-avidity binding to beta-amyloid and increased frequency of type 4 allele in late-onset familial Alzheimer disease. Proc Natl Acad Sci U S A 90:1977-1981.

Tumati S, Martens S, and Aleman A. 2013. Magnetic resonance spectroscopy in mild cognitive impairment: systematic review and meta-analysis. Neurosci Biobehav Rev 37:2571-2586.

Wang L, Zang Y, He Y, Liang M, Zhang X, Tian L, Wu T, Jiang T, and Li K. 2006. Changes in hippocampal connectivity in the early stages of Alzheimer's disease: evidence from resting state fMRI. Neuroimage 31:496-504.

Weis J, Bruvold M, Ortiz-Nieto F, and Ahlstrom H. 2014. High-resolution echo-planar spectroscopic imaging of the human calf. PLoS One 9:e87533.

Yu J, Su T, Zhou T, He Y, Lu J, Li J, and He R. 2014. Uric formaldehyde levels are negatively correlated with cognitive abilities in healthy older adults. Neurosci Bull 30:172-184.

Zhang B, Li M, Sun ZZ, Zhu B, Yuan L, Wang Y, and Xu Y. 2009. Evaluation of functional MRI markers in mild cognitive impairment. J Clin Neurosci 16:635-641.

Peer] reviewing PDF | (2015:04:4733:1:0:NEW 19 Jul 2015) 


\section{Table $\mathbf{1}_{\text {(on next page) }}$}

Table 1: Demographic Data and Patient characteristics

1. $\mathrm{CN}$ = cognitively normal control; $\mathrm{aMCl}=$ amnestic Mild Cognitive Impairment; $\mathrm{MMSE}=$ Mini Mental State Examination; MoCA = Montreal cognitive assessment; HAMD = Hamilton Depression Scale; $C D R=$ Clinical Dementia Rating; $A D L=$ Activities of daily living; ADAS-Cog $=$ Alzheimer's Disease Assessment Scale-Cognitive subscale. 2.* aMCl is significantly different from $\mathrm{CN}$ at $p<0.05$. 3.Median (interquartile range) was reported for continuous variables. 


\begin{tabular}{|c|c|c|c|c|}
\hline & $\begin{array}{l}\mathrm{CN} \\
\mathrm{n}=16\end{array}$ & $\begin{array}{l}\mathrm{aMCI} \\
\mathrm{n}=11\end{array}$ & $p$ & $\mathrm{Z} / \chi^{2}$ \\
\hline No.female(\%) & $4(25)$ & $2(18.2)$ & 0.675 & 0.175 \\
\hline Age,y & 74 (66 to 83$)$ & 79 (69 to 88$)$ & 0.056 & -1.929 \\
\hline Education,y & $15(12$ to 16$)$ & 14 (9 to 16$)$ & 0.342 & 0.119 \\
\hline No.APOE\&2 carriers(\%) & $1(6.3)$ & $2(18.2)$ & & \\
\hline $\begin{array}{l}\text { No.APOE } 3 \\
\text { homozygotes(\%) }\end{array}$ & $12(75)$ & $7(63.6)$ & 0.620 & 0.956 \\
\hline No.APOE $\varepsilon 4$ carriers(\%) & $3(18.8)$ & $2(18.2)$ & & \\
\hline No.FazekasII(\%) & $3(18.8)$ & $3(27.3)$ & 0.601 & 0.274 \\
\hline MMSE & $28.8(24$ to 30$)$ & $25.7(20$ to 30$)$ & $0.013^{*}$ & -2.520 \\
\hline MoCA & $26.9(24$ to 30$)$ & $21.0(14$ to 26$)$ & $0.000^{*}$ & -4.039 \\
\hline $\mathrm{ADL}$ & 20.3 (20 to 23$)$ & $22.8(20$ to 42$)$ & 0.162 & -1.862 \\
\hline Hachinski & $1.8(0$ to 4$)$ & $3.6(0$ to 6$)$ & $0.026 *$ & -2.257 \\
\hline HAMD & $2.5(0$ to 19$)$ & $1.9(0$ to 7$)$ & 0.645 & -0.525 \\
\hline $\mathrm{CDR}$ & $0.0(0.0$ to 0.0$)$ & $0.5(0.5$ to 0.5$)$ & $0.001 *$ & 11.221 \\
\hline ADAS-cog & $5.5(1$ to 14$)$ & $10.2(2$ to 23$)$ & $0.023 *$ & -2.278 \\
\hline Wechsler & $32.0(20$ to 52$)$ & 25.0 (8 to 57$)$ & 0.099 & -1.680 \\
\hline Digit Span Forward & 7.8 (6 to 9$)$ & $6.9(4$ to 10$)$ & 0.134 & -1.540 \\
\hline Digit Span Backward & $5.1(3$ to 8$)$ & $4.2(2$ to 7$)$ & 0.162 & -1.442 \\
\hline
\end{tabular}


Table 2 (on next page)

Table 2: MRS metabolite ratios in median (interquartile range) in aMCl group compared with $\mathrm{CN}$

1. Median (interquartile range) was reported for continuous variables. 2. P values for group comparison are from Mann-Whitney Tests. 3.R = right hippocampus; $L=$ left hippocampus. 4. $\mathrm{NAA}=\mathrm{N}$-acetyl aspartate $; \mathrm{ml}=$ myo-Inositol $; \mathrm{Cr}=$ creatine. $5 . *$ is significantly different between groups at $p \leq 0.05$. 
1

\begin{tabular}{ccccc}
\hline & $\mathrm{CN}$ & $\begin{array}{c}\text { aMCI } \\
\mathrm{n}=16\end{array}$ & $p$ & $\mathrm{Z}$ \\
\hline $\mathrm{NAA} / \mathrm{Cr} \mathrm{R}$ & $2.38(1.68$ to 3.92$)$ & $2.60(2.00$ to 3.43$)$ & 0.134 & -1.530 \\
$\mathrm{NAA} / \mathrm{Cr} \mathrm{L}$ & $2.06(0.13$ to 3.26$)$ & $2.22(1.40$ to 3.37$)$ & 0.680 & -0.444 \\
$\mathrm{mI} / \mathrm{Cr} \mathrm{R}$ & $0.64(0.41$ to 0.78$)$ & $0.72(0.39$ to 0.92$)$ & $\mathbf{0 . 0 5 0 *}$ & -1.977 \\
$\mathrm{mI} / \mathrm{Cr} \mathrm{L}$ & $0.75(0.36$ to 1.37$)$ & $0.79(0.47$ to 1.48$)$ & 0.753 & -0.321 \\
$\mathrm{mI} / \mathrm{NAA} \mathrm{R}$ & $0.28(0.16$ to 0.40$)$ & $0.28(0.12$ to 0.46$)$ & 0.942 & -0.099 \\
$\mathrm{mI} / \mathrm{NAA} \mathrm{L}$ & $0.95(0.13$ to 10.31$)$ & $0.35(0.24$ to 0.57$)$ & 0.753 & -0.321 \\
\hline
\end{tabular}




\section{Table 3 (on next page)}

Table 3: The statistically significant correlations between clinical rating scales, age and the $\mathrm{ml} / \mathrm{Cr}$ ratios from the right hippocampus

1.Only statistically different clinical rating scales between groups were enrolled in this correlations analysis. 2. MMSE $=$ Mini Mental State Examination; $M O C A=$ Montreal cognitive assessment; ADAS-Cog = Alzheimer's Disease Assessment Scale-Cognitive subscale; $C D R=$

Clinical Dementia Rating. 3. $\mathrm{R}=$ right hippocampus. $4 . \mathrm{ml}=$ myo-Inositol $; \mathrm{Cr}=$ creatine. 5. * is significantly different between groups at $p \leq 0.05$. 


\begin{tabular}{|c|c|c|c|c|c|c|c|c|c|c|c|c|}
\hline & \multicolumn{2}{|c|}{ MMSE } & \multicolumn{2}{|c|}{$\mathrm{MoCA}$} & \multicolumn{2}{|c|}{ Hachinski } & \multicolumn{2}{|c|}{ ADAS-cog } & \multicolumn{2}{|c|}{ CDR } & \multicolumn{2}{|c|}{ Age } \\
\hline & Sig & $r_{\mathrm{s}}$ & Sig & $r_{\mathrm{s}}$ & Sig & $r_{\mathrm{s}}$ & Sig & $r_{\mathrm{s}}$ & Sig & $r_{\mathrm{s}}$ & Sig & $r_{\mathrm{s}}$ \\
\hline $\begin{array}{c}\mathrm{mI} / \mathrm{Cr} \\
\mathrm{R}\end{array}$ & 0.953 & -0.012 & $\underline{0.025 *}$ & -0.431 & 0.719 & -0.073 & 0.522 & 0.129 & 0.165 & 0.275 & 0.678 & -0.084 \\
\hline Age & $\underline{0.007 *}$ & -0.508 & $\underline{0.035 *}$ & -0.407 & 0.081 & 0.342 & $\underline{0.014 *}$ & 0.469 & 0.109 & 0.315 & - & - \\
\hline
\end{tabular}


Table 4(on next page)

Table 4: The effects of APOE and age on the association between $\mathrm{ml} / \mathrm{Cr}$ ratios and clinical rating scale (the scores of MoCA)

1.MoCA $=$ Montreal cognitive assessment. $2 \cdot \mathrm{R}=$ right hippocampus. $3 . \mathrm{ml}=$ myo-Inositol $; \mathrm{Cr}$

$=$ creatine. $4 . *$ is significantly different between groups at $p \leq 0.05$. 
1

\begin{tabular}{llll}
\hline & & Sig & \multicolumn{1}{l}{$r_{\mathrm{s}}$} \\
\hline $\mathrm{mI} / \mathrm{Cr} \mathrm{R} * \mathrm{MoCA}$ & & $0.025^{*}$ & -0.431 \\
\hline (controlling for age) & & 0.073 & -0.358 \\
\hline (group by APOE genotype) & $\begin{array}{l}\text { non- } \varepsilon 4 \text { carrier } \\
\varepsilon 4 \text { carrier }\end{array}$ & 0.152 & -0.316 \\
& 0.219 & -0.667 \\
\hline $\begin{array}{l}\text { (group by APOE genotype and controlling for } \\
\text { age) }\end{array}$ & non- $\varepsilon 4$ carrier & 0.115 & -0.354 \\
& $\varepsilon 4$ carrier & 0.138 & -0.862 \\
\hline
\end{tabular}

2 


\section{1}

The localization of MRS on hippocampus

(A): Different VOIs for NAA ( red ) and $\mathrm{ml}$ ( white ) for localization. Shimming ( green ) and REST slabs ( blue ) are also shown above. (B), (C): Different VOls for NAA ( red ) and ml ( yellow ) co-registered in FreeSurfer native space.

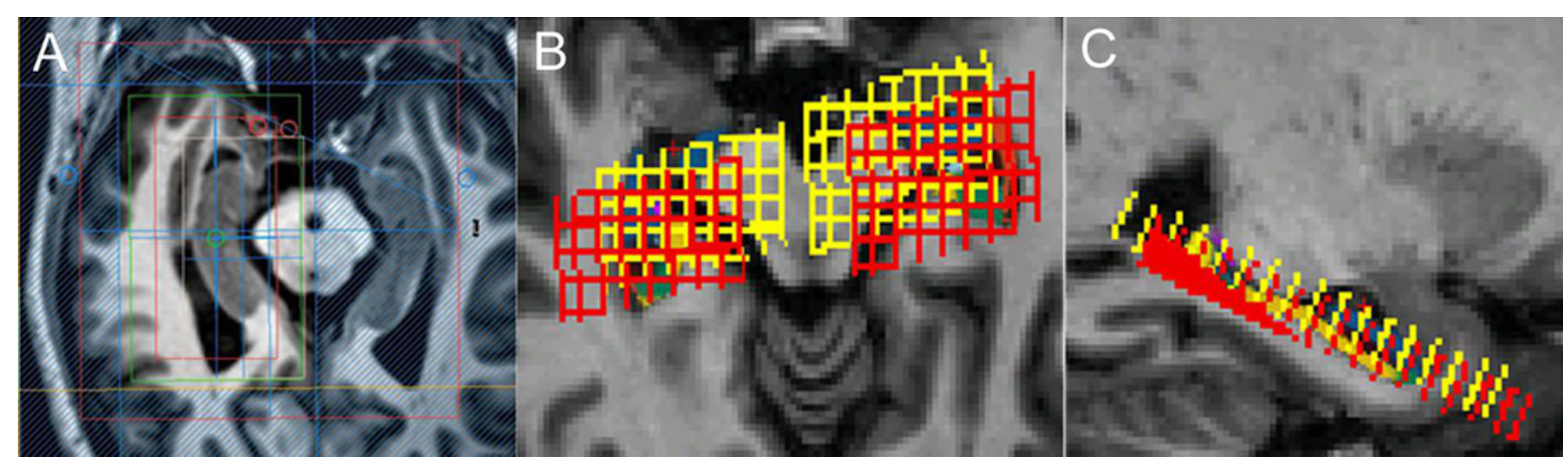


2

The MRS result from bilateral hippocampus

The representative example MRS resulting from the left hippocampus of the aMCI and CN subject is respectively shown in (A) and (B), and the group statistical characteristics are shown in (C).The MRS resulting from right hippocampus are showed in (D), (E) and (F). All spectra are scaled to the height of the reference peak $\mathrm{Cr}$, shown with a dotted line. Spectra from the right hippocampus demonstrates the increased $\mathrm{ml} / \mathrm{Cr}$ in a patient with $\mathrm{aMCl}$ (D) compared with $\mathrm{CN}(\mathrm{E})$ at $\mathrm{p}=0.05(\mathrm{~F})$.
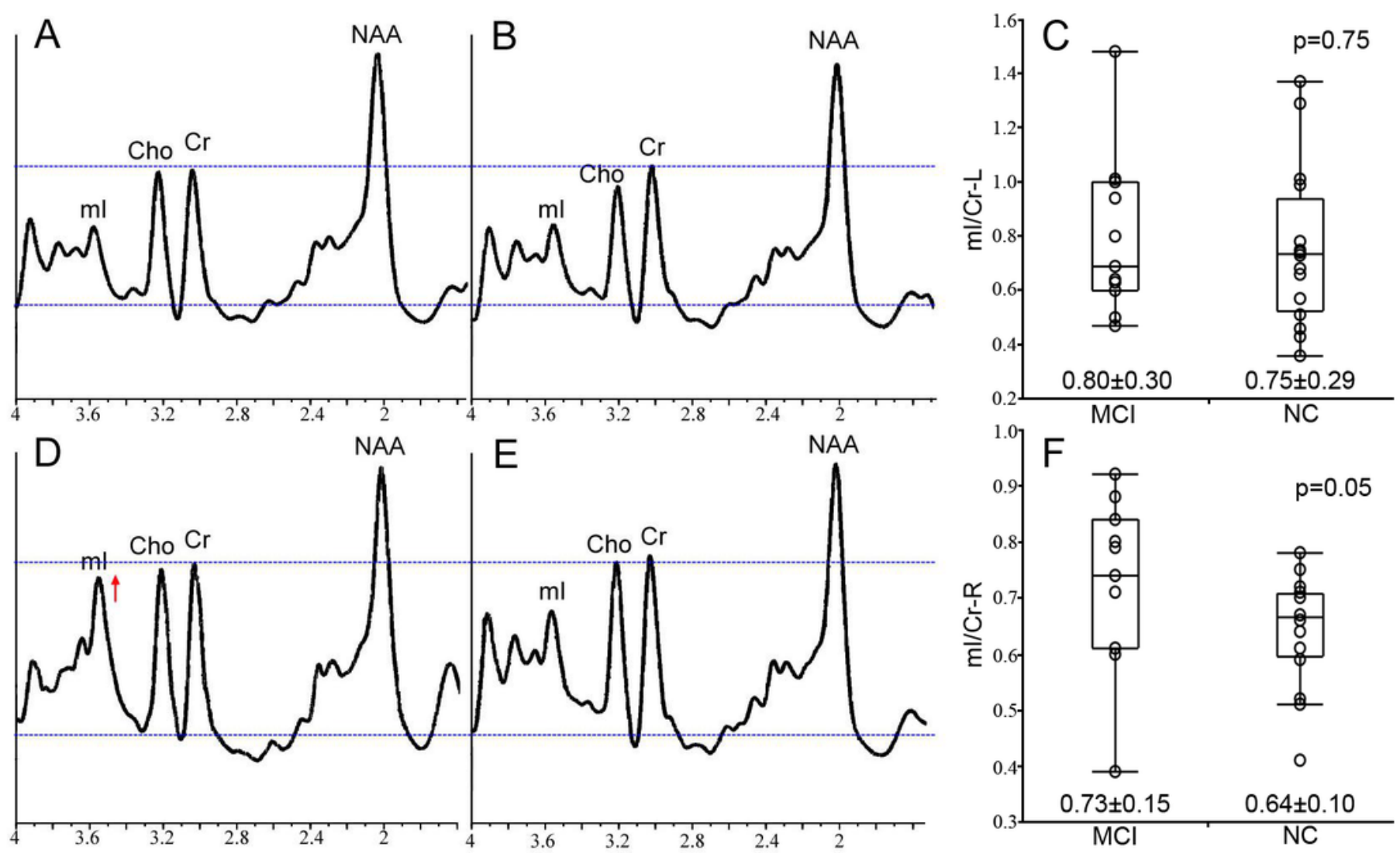


\section{3}

The difference of $\mathrm{ml} / \mathrm{Cr}$ and MoCA between APOE $\varepsilon 4$ carriers and non-carriers

The statistical characteristics of $\mathrm{ml} / \mathrm{Cr}$ from right hippocampus of APOE $\varepsilon 4$ carriers and noncarriers are shown in (A). The cognitive performances of APOE $\varepsilon 4$ carriers and non-carriers are shown in (B).
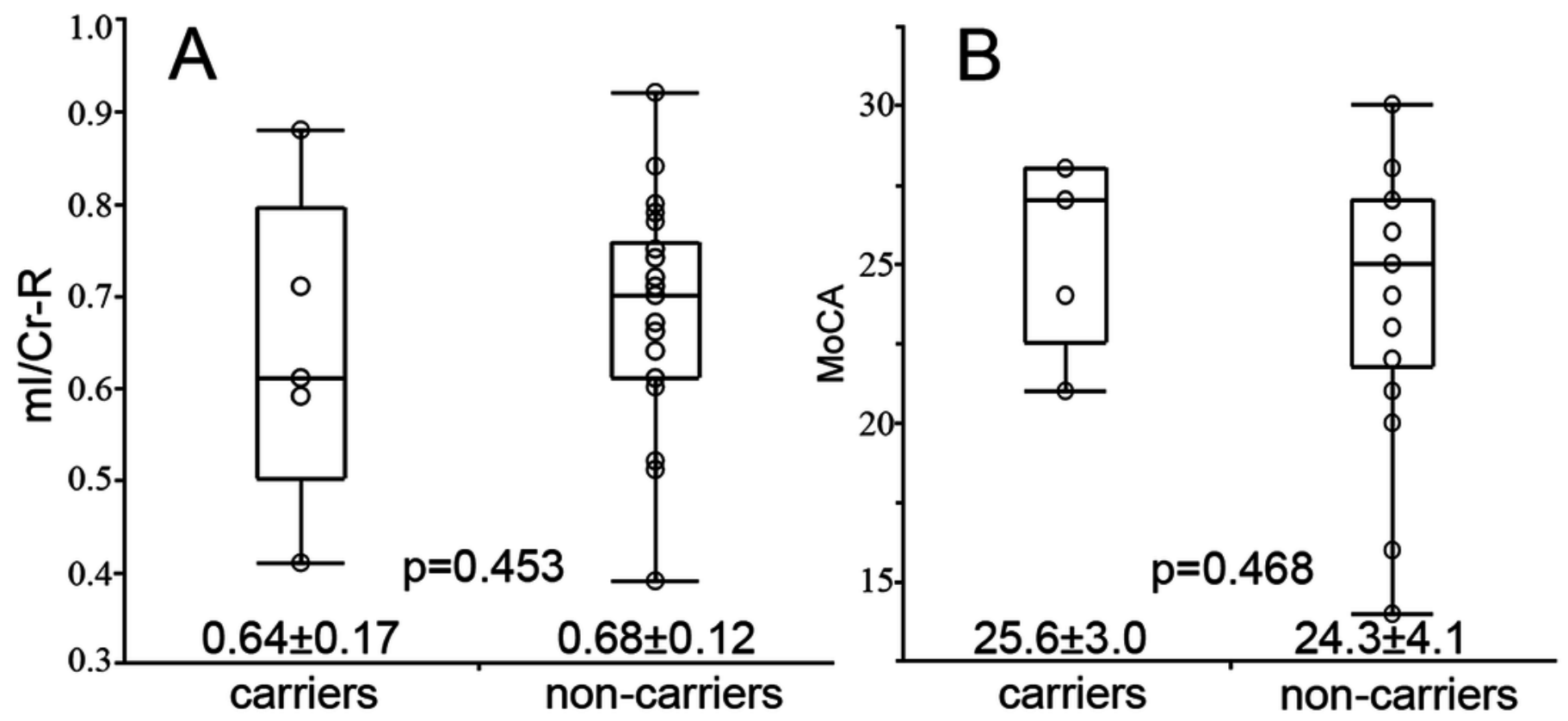
4

The correlation between $\mathrm{ml} / \mathrm{Cr}$ and MoCA

The correlation between $\mathrm{ml} / \mathrm{Cr}$ from right hippocampus and MoCA are shown in APOE $\varepsilon 4$ carriers (A) and non-carriers (B), respectively.
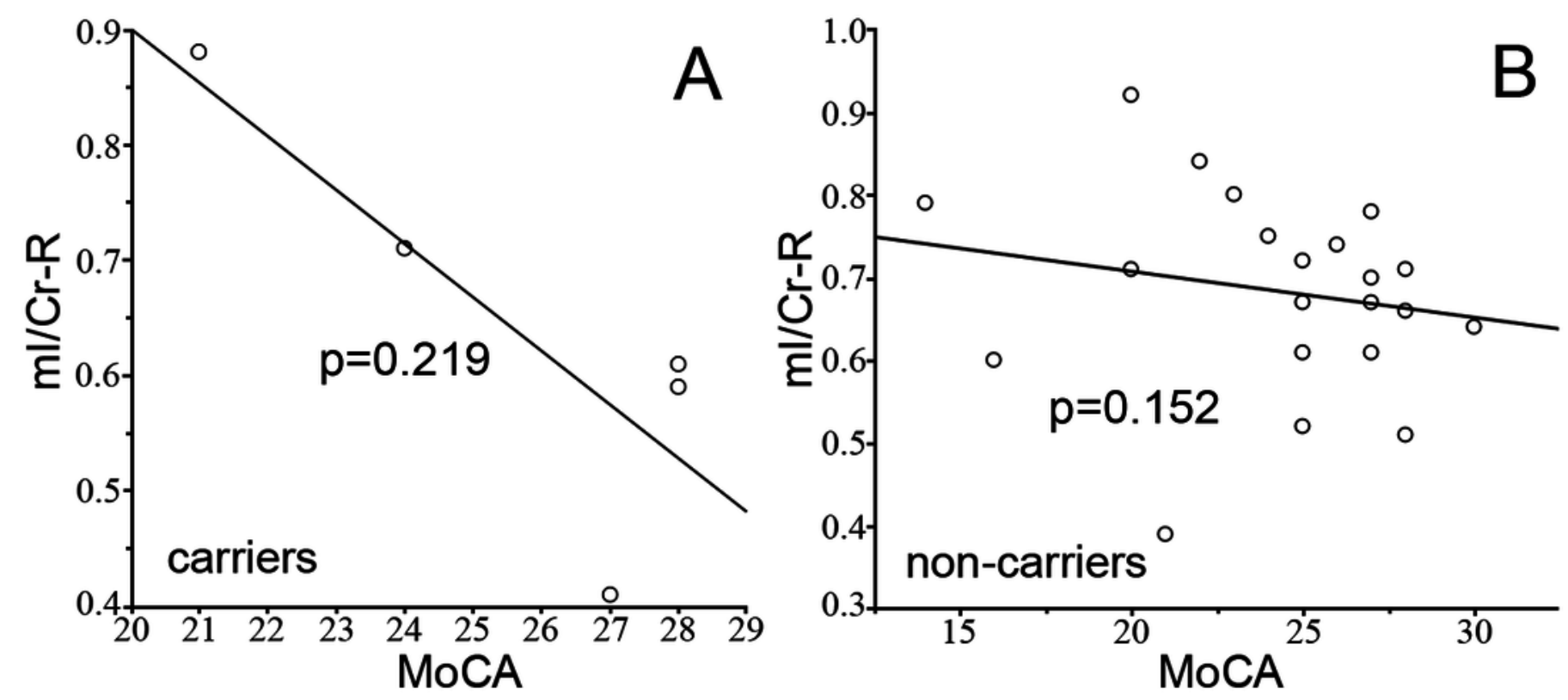